\title{
Lake water level increase during spring affects the breeding success of bream Abramis
} brama (L.)

Wolfgang Nikolaus Probst ${ }^{* \dagger}$, Stefan Stoll ${ }^{*}$, Lars Peters $^{+}$, Philipp Fischer ${ }^{\ddagger}$, Reiner Eckmann ${ }^{*}$

*Limnological Institute, University of Konstanz, 78457 Konstanz, Germany.

Tel.: +49 7531 883216; Fax: +49 7531

${ }^{+}$University of Bielefeld; Universitätsstrasse 25, 33615 Bielefeld, Germany

$\$$ Alfred-Wegener-Institute for Polar and Marine Research, Biologische Anstalt Helgoland, Kurpromenade 201, 27498 Helgoland, Germany

${ }^{\dagger}$ Author to whom correspondence should be addressed. 883533; email: niknaison@ web.de

Key words: spawning substratum, hydrology, climate, breeding, cyprinids, Lake Constance

This paper has not been submitted elsewhere in identical and similar form, nor will it be during the first three month after its submission to Hydrobiologia. 


\section{Abstract}

In Lake Constance Eurasian bream Abramis brama (L.) spawn in very shallow littoral areas by the beginning of May. They attach their adhesive eggs to pebble and cobble substratum at less than $40 \mathrm{~cm}$ depth. Increasing water levels before spawning inundate bare substratum to which bream eggs may attach better than to deeper substratum covered by epilithon.

Consequently, the water level increase prior to spawning should determine the amount of pristine spawning substratum available to bream and thus influence their breeding success. To test this hypothesis, the influence of hydrology and climate on the abundance of age- 0 bream was combined with results from field investigations on the egg survival and abundance of age-0 bream. A strong positive correlation between the mean water level increase during the spawning season of bream (April-May) and the abundance of juvenile bream was found. By contrast, the absolute water level during spawning and during the nursery stage in summer, the cumulative temperature during the egg, larval and juvenile stages and two North Atlantic Oscillation (NAO) indices did not affect the abundance of juvenile bream. The field investigations confirmed that bream eggs attach better to and have higher survival rates on bare substratum than on substratum with epilithon cover. Accordingly, eggs within a spawning habitat of bream were most abundant between $10-20 \mathrm{~cm}$ depth, where the epilithon cover was lower than at depths exceeding $30 \mathrm{~cm}$. The results of this study confirm an adverse influence of epilithon cover on the attachment and subsequent survival of bream eggs and emphasize the importance of spring inundations for the successful breeding of bream. 


\section{Introduction}

The year-class strength of fish is usually determined during their early life history stages (Leggett \& Deblois, 1994; Jennings et al., 2001; Nunn et al., 2003) because the highest rates of mortality within a cohort usually occur during the egg, larval and juvenile stages. Among the environmental factors, which have been found to strongly affect the survival of age-0 fish, water temperature, food and predator abundance are well investigated (Nunn et al., 2003; Paxton et al., 2004; Fulford et al., 2006a; Fulford et al., 2006b). Some research has also focused on the influence of water level fluctuations for the survival of larvae and juveniles (Clark et al., 1998; Ozen \& Noble, 2002; Argillier et al., 2004; Clark et al. 2008), but only few studies investigated the influence of water level fluctuations on the survival of fish eggs (Dziekonska, 1956; Winfield et al., 2004; Kahl et al., 2008). Most of the latter studies focused on the influence of decreasing water levels during egg incubation, but to our knowledge only one study investigated the influences of increasing water levels prior to spawning (Gafny et al., 1992).

In Lake Kinneret, lake sardine Acanthobrama terrasanctae Steinitz 1952 spawn in the very shallow littoral zone where the low algal cover of freshly inundated shore areas allowed optimal egg attachment to rocky substrate. Consequently, the water level increase prior to spawning strongly influenced the availability of pristine spawning substratum, which affected the survival of $A$. terrasanctae eggs. However, the study of Gafny et al. (1992) failed to establish a relationship between the epilithon cover on the spawning substratum and the year class strength of lake sardine and thus could not validate the relevance of their results in a long term data analysis. Based on the mechanistic explanation proposed by Gafny et al. (1992) the present study intends to fill this gap by providing a 12 year data analyses on the influence of spring water level increase and breeding success of bream Abramis brama (L.).

Bream spawn in very shallow, near-shore waters of less then $0.5 \mathrm{~m}$ depth (Poncin et al., 1996; Kafemann et al., 1998; Hladik \& Kubecka, 2004). Spawning commences when 
water temperatures reach about $14{ }^{\circ} \mathrm{C}$ (Herzig \& Winkler, 1986; Hladik \& Kubecka, 2004; Nõges \& Jarvet, 2005). In the absence of macrophytes, bream lay their eggs on stony substrates (Wittkugel, 2002; Hladik \& Kubecka, 2004). In Lake Constance, spawning aggregations of mature bream can be observed along shorelines in late April and early May. Spawning usually coincides with an increment in water level caused by alpine melt-water runoff and spring precipitation.

A pronounced increment in lake water level immediately before the spawning of bream may allow bream to access freshly inundated, bare substrata, which according to Gafny et al. (1992) should promote the survival of their eggs. Consequently, the water level increase during spring should be correlated with the subsequent abundance of age- 0 bream in summer. To test this hypothesis, the abundances of age-0 bream at two sites in Lake Constance were related to several hydrological and climate data between 1997 and 2008. To provide supplemental evidence for adverse effects of epilithon, a field experiment compared the egg attachment and survival on artificial substrata with and without epilithon cover. Finally, the distribution of bream eggs within a spawning habitat was investigated to test whether their abundance differed along a depth-dependent gradient of epilithon cover. According to our hypothesis, we assumed that most eggs should be found at the most shallow depth with the lowest epilithon cover.

\section{Methods}

\section{Study sites}

Upper Lake Constance is an oligotrophic, warm monomictic prealpine lake in central Europe with a surface area of $476 \mathrm{~km}^{2}$ and a mean depth of $100 \mathrm{~m}$ (Mürle et al., 2004). The catchment area of the Lake Constance compasses approx. 11,500 km² (Mürle et al., 2004), from which 
$62.4 \%$ derive from alpine regions (Ostendorp et al., 2004). Next to Lake Walensee, Lake Constance is the only non-regulated large lake in the alpine region (Ostendorp et al., 2004) and therefore the lake water level fluctuates usually around $150 \mathrm{~cm}$ throughout the year with highest water levels during June or July and lowest levels in February or March.

The annual catches of juvenile bream were averaged from beach seining campaigns at two sites in the western part of Upper Lake Constance (Fig.1). The site BIRNAU $\left(47^{\circ} 44.78^{\prime} \mathrm{N}, 09^{\circ} 12.68^{\prime} \mathrm{E}\right)$ is located on the Northern shore of Lake Constance below the monastery of Birnau and the site FELS $\left(47^{\circ} 41.22^{\prime} \mathrm{N}, 09^{\circ} 12.45^{\prime} \mathrm{E}\right)$ is located south of Island of Mainau. The experiment on egg attachment and survival was conducted in the shallow littoral zone near the Limnological Institute of the University of Konstanz $\left(47^{\circ} 41.72^{\prime} \mathrm{N}, 09^{\circ} 11.65^{\prime} \mathrm{E}\right)$. The bream egg and epilithic biomass distribution along a depth gradient was sampled along five transects in a natural spawning habitat of bream north of the village of Litzelstetten $\left(47^{\circ} 43.33^{\prime} \mathrm{N}, 09^{\circ} 10.75^{\prime} \mathrm{E}\right)$. Bream are known to spawn in this area between the end of April and middle of May and all eggs found attached to cobbles and stones can almost exclusively be attributed to bream (Wittkugel, 2002).

\section{Age-0 bream abundance and environmental factors}

Bream were caught at the two locations BIRNAU and FELS in July and August 1997 until 2008 with a $10 \mathrm{~m}$ long beach seine with a mesh size of $6 \mathrm{~mm}$ from knot to knot. Due to bad weather or high water levels, beach seining was not always performed in both July and August within each year. Hence for each year the earliest available information on the abundance of juvenile bream was used in the GLM. This approach was chosen to minimize the impact of larval and juvenile bream mortality during the summer, which may reduce the potential signal of breeding differences in years with high and low spring water levels. For each month the beach seine campaign consisted of 3 replicate hauls from $1 \mathrm{~m}$ depth to the 
shore at the two locations at day and night resulting in twelve hauls per month. The number of juvenile bream was recorded for each haul and entered into the GLM.

Data on daily water temperatures in the littoral zone of Lake Constance were not continuously available between 1997 and 2008, therefore monthly mean water temperatures at $0.5 \mathrm{~m}$ depth measured daily in the north-western part of the lake from 2004 until 2007 were related to the monthly mean air temperatures $2 \mathrm{~m}$ above ground measured by the Konstanz meteorological station of the German Weather Service. The monthly mean of the water temperatures from 2004 to 2007 related significantly to the air temperatures (water temperature $\left({ }^{\circ} \mathrm{C}\right)=1.149 *$ air temperature $\left.\left({ }^{\circ} \mathrm{C}\right)-3.176, \mathrm{~N}=48, \mathrm{R}^{2}=0.85, \mathrm{p}<0.001\right)$ and hence the air temperatures were used to calculate the cumulative degree days for larval and juvenile bream during summer (May-August). Cumulative degree days were calculated daily from the 1st of May until the 31st of August using the mean air temperatures of the according month for each day.

Monthly mean water levels from the water level gauge in the harbour of Konstanz were available since 1997. The origin of the gauge is set at $391.85 \mathrm{~m}$ a.s.l. (zero level NAP, Amsterdam, North Sea). Referring to the origin of the harbour gauge, the annual mean lake level is $3.27 \mathrm{~m}$. The increase in water level between April and May (SpWLI) was used as a descriptor for the quantity of high-quality spawning habitat with low epilithon cover. The mean water level for each month was calculated from daily water level readings from the first to the last day of the according month. The SpWLI was calculated as the difference between the mean WL in May and the mean WL in April. The mean water level in May (WL May) was used as a descriptor for the quantity of total available spawning habitat. The summer water level (SuWL) was used as a descriptor of the quantity of nursery habitat available to age-0 bream.

The monthly NAO indices were obtained from the web sites of Jim Hurrell and Tim Osborn from the Climate Research Unit, School of Environmental Sciences, University of 
East Anglia (http://www.cru.uea.ac.uk/cru/data/nao.htm). This NAO index describes the differences in air pressure between the Icelandic Low and the Azores High. High NAO indicate an active transport of moist and warm Atlantic air masses to Northern Europe resulting in high precipitation and relatively warm (winter) or cool (summer) temperatures (Hurrell, et al., 2003). The NAO index has shown to influence many ecological processes in freshwater systems (Straile \& Stenseth, 2007) and thus may have an influence on the breeding success of bream.

\section{Artificial substrate experiment (2005)}

Eggs were obtained from one female (total length $50 \mathrm{~cm}$ ) caught on 05.05 .2005 and fertilised with sperm of two males (total lengths $55 \mathrm{~cm}$ and $52 \mathrm{~cm}$ ) caught on 01.05.2005, which had been kept in a $40 \mathrm{~m}^{3}$ basin until they were stripped. Unfortunately, no second ripe female could be caught, to mitigate possible maternal effects on egg quality. However, fertilized eggs, which were not used for the experiment, were bread in the laboratory. Almost all eggs hatched, thus the fertilization rate of the eggs was considered as high.

Ceramic tiles (unglazed, $4.6 \times 4.6 \mathrm{~cm}$ ) were mounted on three aluminium trays that were deployed in the littoral zone. To obtain various degrees of epilithon cover, eight tiles were placed randomly on each tray four weeks before the artificial fertilisation. Eight additional tiles were added weekly to each tray, resulting in tile exposure periods from one to four weeks ( 8 tiles per week x 3 trays $x 4$ weeks $=96$ tiles). According to water level fluctuations, the positions of the aluminium trays were adjusted so that the tiles remained at $30 \mathrm{~cm}$ water depth during the entire period of their exposure in the lake.

One day before the artificial fertilisation of the bream eggs, all tiles were recovered from the lake. Half of each tiles surface was sampled for determination of Chlorophyll $a(\mathrm{Chl}$ a), ash-free dry mass (AFDM) and inorganic matter (IM) content. Sampling was done with a glass scraper, and the scraped area was then used as the control surface for egg attachment. 
All 96 half-scraped individually marked tiles were placed randomly within a 73 x $54 \mathrm{~cm}$ plastic tub filled with fresh lake water. The fertilised eggs (150 ml, approx. 25,000 eggs) were added to the tub and allowed to settle on the tiles under continuous gentle stirring. The water within the tub was maintained at lake water temperature. After a settlement period of 1.5 hours, the number of eggs attached to the scraped and unscraped areas of each tile was determined. Subsequently, the tiles were placed onto the aluminium trays and set back into the lake in randomised order. Water temperature was measured each at $25 \mathrm{~cm}$ water depth. The number of living eggs on each tile was counted at 2 to 3 day intervals while carefully lifting the trays to the surface. Eggs with a brownish-golden colour were considered as viable eggs. During the egg incubation two tiles were lost, thus data from 94 egg-carrying tiles was obtained. Survival rates of eggs were calculated from viable eggs remaining on the tiles as a percentage of initially attached eggs. Hatching of the larvae started on day 8 post fertilization (dpf). At this day, the experiment was stopped, and the viable eggs counted on day 8 were considered as having hatched successfully. During the entire experiment no spawning of bream or other fish was observed at the experimental site and no spawn from fish in the lake was detected on the tiles.

\section{Field investigation on bream egg distribution}

To map the depth distribution of bream eggs within a natural bream spawning habitat five transects perpendicular to the shoreline were sampled between 18.05.2005 and 20.05.2005. Before setting the transects the shoreline was screened until bream eggs were found. Sampling along the transects occurred within depth strata of $0-10,10-20,20-30$ and $30-$ $40 \mathrm{~cm}$. The transects were at least $20 \mathrm{~m}$ apart and covered a distance of approx. $150 \mathrm{~m}$. No bream eggs were found below $40 \mathrm{~cm}$ water depth. All eggs detected on stones were assumed to be bream eggs, because bream are the earliest shallow water spawners in the lake, and spawning aggregations of bream had been observed near the sampling site on 03.05.2005. 
From each depth stratum within each transect, ten stones were sampled randomly to determine the abundance of eggs. For this purpose, rings with predefined areas $\left(5.73 \mathrm{~cm}^{2}\right)$ were set onto the stone surface to enclose the maximum number of eggs attached to the stone. Epilithon biomass was sampled from 6 randomly picked stones within each depth stratum with a brush sampling device (Peters et al. 2005). Two brush samples were pooled into one $100 \mathrm{ml}$ polyethylene bottle. All samples were processed in the lab within 24 hours.

\section{Biomass analyses}

Samples of epilithon from the experimental tiles and the field transects were treated as described in Peters et al. 2005. The samples were filtered onto pre-combusted (five hours at $550{ }^{\circ} \mathrm{C}$ ) glass-fibre filters (Schleicher \& Schuell GF6 $\varnothing 25 \mathrm{~mm}$ ) for AFDM and IM determination. To include fine sediments and suspended particles, each sample was stirred with a magnetic stirrer and subsamples $(10 \mathrm{ml})$ were taken for $\mathrm{Chl} a$, AFDM and IM analysis. After filtration, the AFDM/IM samples were dried for $24 \mathrm{~h}$ at $105^{\circ} \mathrm{C}$ for determination of dry weight. Subsequently, samples were combusted at $550^{\circ} \mathrm{C}$ for five hours, and AFDM was determined as the difference between the weight of the combusted sample and the dry mass on the filter. IM was determined as the difference between the weight of the combusted sample and the filter weight. $\mathrm{Chl} a$ samples were stored in the dark and frozen at $-20{ }^{\circ} \mathrm{C}$ until processed. Chl $a$ was extracted with $90 \%$ acetone for $24 \mathrm{~h}$ and measured in a spectrophotometer. Values were corrected for pheopigment content (Lorenzen, 1967).

\section{Statistical analysis}

All data were tested for homogeneity of variances with the Cochran- and Bartley-test. For data, which violated the prerequisite of homogenous variances, non-parametric tests were applied. For data with sample sizes $\mathrm{n}>50$ (data of $\mathrm{Chl} a$, AFDM and IM on the artificial substrates), normality was tested with Kolmogorov-Smirnoff-test (Lozan \& Kausch, 1998). 
For all other data with sample sizes $\mathrm{n}<50$, no test for normality was performed. Instead, the central limit theorem was assumed (Lozan \& Kausch, 1998), because data from transects at depth were means of replicated samples.

To analyse the influence of hydrological and climate factors on the survival of YOY bream, a general linear model (GLM) related the categorical factors Loc and Tim and continuous factors SpWLI, WL May, SuWL, DD, SNAO and WNAO to the abundance of age-0 bream as response variable (for a detailed description of factors and response variable please refer to Table 1). Using the "step"-routine in the statistical software-package R, the complexity of the general linear model was reduced stepwise until a minimal Akaike Information Criterion (AIC) was achieved.

Chl $a$, AFDM, and IM contents of epilithon on the tiles after one to four weeks of exposure were compared using Kruskal-Wallis ANOVA, because the data failed to meet the parametric ANOVA requirements of homogenous variances. For the same reason, the attachment rates on clean and epilithon-covered tiles (0, 1, 4, 6 and $8 \mathrm{dpf})$ and the survival rates of eggs (1, 4, 6 and $8 \mathrm{dpf})$ were compared with non-parametric Wilcoxon-test for paired samples.

AFDM, IM, Chl $a$ and bream eggs abundances in the natural spawning habitat were compared between different depth strata and transects with two-way ANOVAs and subsequent Tukey-HSD-test.

\section{Results}

\section{Influence of environmental factors on juvenile bream abundance}

The monthly mean CPUE of age-0 bream ranged from 0.0 bream per haul ( \pm 0.0 S.D.) in July 1998 to 23.5 bream per haul ( \pm 28.7 S.D.) in July 1999 (Fig.2), resulting in an average catch 
of 4.5 bream per haul ( \pm 6.6 S.D.). After five iterations a minimal AIC of 705.74 was achieved (Table 2). The final GLM model included the factors Tim, Loc, SpWLI and the interaction between Tim and Loc. Mean CPUE were different between locations and time of the day, being significantly higher at day (7.4 bream per haul \pm 17.9 S.D.) than at night (1.7 bream per haul \pm 3.7 S.D.) and at the site BIRNAU (6.5 bream per haul \pm 16.7 S.D.) than at the site FELS (2.6 bream per haul \pm 8.1 S.D., Table 2$)$. The only hydrological or climatic factor influencing the CPUE of juvenile bream was SpWLI. Consequently, the mean CPUE from each year was strongly related to SpWLI (Fig.3). Contrary, neither SuWL, WL May, DD, SNAO W NAO contributed significantly to the explained variation of the GLM (Table 2).

\section{Egg attachment and survival on artificial substrate}

During the exposure of the tiles between 07.04.2005 and 19.05.2005, the lake level increased by $36 \mathrm{~cm}$. During the same time interval, water temperature in the shallow littoral zone ranged from $6.7^{\circ} \mathrm{C}$ to $13.9^{\circ} \mathrm{C}$, peaking at the beginning of May, when spawning of bream was observed at two nearby sites. During the incubation of bream eggs on tiles, the average temperature was $12.1^{\circ} \mathrm{C}( \pm 1.8$ S.D.). At this temperature range, hatching of bream eggs commences at $8 \mathrm{dpf}$ (Herzig \& Winkler, 1986).

In the fourth week of tile exposure shortly before the start of the experiment, chironomid larvae grazed heavily on the epilithon upon the tiles. Therefore the tiles did not differ significantly in either organic or inorganic matter content (Kruskal-Wallis ANOVA: $\left.\mathrm{AFDM} \mathrm{H}_{3,94}=5.165 \mathrm{p}=0.161 ; \mathrm{IM} \mathrm{H}_{3,94}=2.240, \mathrm{p}=0.524\right)$. The mean Chl $a$, AFDM and IM on the tiles were $0.213 \mu \mathrm{g} \mathrm{cm}^{-2}( \pm 0.041$ S.D. $), 1.154 \mathrm{mg} \mathrm{cm}^{-2}( \pm 0.745$ S.D.) and 11.607 $\mathrm{mg} \mathrm{cm}{ }^{-2}( \pm 38.354$ S.D.), respectively. Because no difference in epilithon cover was evident, data from all exposed tiles were pooled in the subsequent analysis of egg attachment and survival. 
Approximately twice as many bream eggs attached to scraped control areas than to areas of the tiles overgrown with epilithon (Fig. 4A; Wilcoxon-test; $\mathrm{N}=94, \mathrm{~T}=126, \mathrm{Z}=$ 4.03, $\mathrm{p}<0.001)$. High detachment of eggs occurred during the first day of the experiment (about $85 \%$ and $93 \%$ on bare end epilithon covered tile surfaces, respectively), while during the following days detachment rates were lower. High rates of mortality occurred also between 4 and 6 dpf, when smothering of eggs by resuspended sediment was observed.

Percentage survival of bream eggs was generally low, but on 8 dpf survival was about 4.5 times higher on the clean tile areas than on tile areas with epilithon coverage $(0.86 \% \pm$ 0.20 S.E. and 0.19\% $\%$ 0.09 S.E., respectively, Fig.4B, Table 3). Considering the higher attachment success of eggs on clean tile surfaces, the absolute number of attached eggs surviving until hatch differed by a factor of eight between clean and epilithon-covered tile surfaces.

\section{Depth distribution of eggs and epilithon at the natural spawning site}

Chl $a$, AFDM and IM increased significantly with depth (Fig.5A-C; ANOVA: Chl $a$ F $_{3,56}=$ 9.57, $\left.\mathrm{p}<0.001 ; \mathrm{AFDM} \mathrm{F}_{3,56}=4.20, \mathrm{p}<0.01 ; \mathrm{IM} \mathrm{F}_{3,56}=11.37, \mathrm{p}<0.001\right)$ and the lowest $\mathrm{Chl}$ $a$, AFDM and IM contents was found between 0 and $20 \mathrm{~cm}$ depth. Accordingly, attached bream eggs were found almost exclusively between 10 and $30 \mathrm{~cm}$ depth and only one single egg was found below $30 \mathrm{~cm}$ within the five transects (Fig. 5D).

\section{Discussion}

The present results are in every aspect congruent with the hypothesized influence of SpWLI on the egg survival and resulting abundance of age-0 bream: Egg attachment and survival was impaired by epilithon cover, accordingly the majority of bream eggs were found in depths with the lowest epilithon cover, and high SpWLI resulted in years with high age-0 bream 
abundance. All these results combined provide strong evidence, that epilithon cover influences the egg survival of bream. By contrast, the absolute water level during spawning in May (WL May) and the water level during summer was not related to the abundance of juvenile bream. Therefore the absolute amount of inundated littoral area during the spawning and nursery period seems to be of minor importance for bream. Instead, the availability of freshly inundated habitat with clean substratum appears to be crucial for their breeding success of bream.

Low water levels during summer may limit the availability of nursery habitat with complex structures and rich food abundance (Wilcox \& Meeker, 1992). Under these circumstances a low water level during summer should lead to high rates of mortality due to poor growth and high predation rates. However, the abundance of juvenile bream in July or August was not related to the absolute water level in June and July. Therefore the availability of nursery habitat in June and July does not seem to be a limiting factor for the survival of larval and juvenile bream. Nonetheless, predation on larvae and juveniles during the summer may significantly modify the subsequent year class strength of bream and may also account for a considerable proportion of the unexplained variance in the GLM. It remains to be assessed to which extent the mortality rates during the egg, larval and juvenile stage contribute to the variation in the year-class strength of bream recruiting to the fishery. Nonetheless, this study clearly demonstrates that the period of egg incubation is a bottleneck in bream life-history.

Climatic factors did not affect the abundance of juvenile bream in Lake Constance. This is probably due to the fact that Lake Constance bream is not at the northern boundary of its distribution range and hence they is not limited by temperatures during summer, even in cooler years. Though annual variations in water temperatures may cause differences in growth between years (Mills \& Mann, 1985), in Lake Constance variation in bream growth may not be severe enough to cause differences in survival. From May to June, water temperatures in 
Lake Constance usually rise from 12 to $17^{\circ} \mathrm{C}$, which is in the range of normal embryo and larval development of bream (Herzig \& Winkler, 1986; Kucharczyk et al., 1997).

Accordingly, neither the summer nor the winter NAO was related to juvenile bream abundance. It is generally assumed, that on many ecological processes the winter NAO has more severe impacts than the summer NAO (Straile \& Stenseth, 2007). In winter most organisms are constrained by physical factors, whereas in summer biological interactions become more relevant. For bream in Lake Constance the influence on winter NAO may cause variation in winter mortality and condition of spawners, which in turn may affect the number and quality of spawned eggs. However, the present study does not provide any indication of NAO related variations in the abundance of juvenile bream. This may be due to the fact, that the spawning population of bream is not strongly affected by winter climate conditions or that no relationship between the number of spawners and juveniles exists. According to the insignificant influence of water temperatures during summer, the mean summer NAO also had no effect on juvenile bream abundance.

Though strong influences of temperatures on year class strength of freshwater fish have been found in other studies (Mills \& Mann, 1985; Aalto \& Newsome, 1993; Argillier et al., 2004; Paxton et al., 2004), there is increasing evidence for the importance of hydrological factors for the formation of year class strength. Nunn et al. (2003) observed a negative correlation between river discharge and year class strength of three cyprinid fish species in a North-English lowland river and concluded that river discharge rates may affect their year class strength more severely than temperature effects per se. Kahl et al. (2008) and Winfield et al. (2004) found a strong relationship between the reduction of water level during egg incubation and the year class strength of roach and whitefish, respectively. Nöges \& Jarvet (2005) investigated the onset of bream spawning in Estonian lakes and rivers and found that bream spawn earlier in years with high spring water levels. Though the authors related this 
advance in spawning season to flooding related temperature effects, the study provides evidence that bream adjust their spawning behaviour to the hydrological regime.

Besides the influences of SpWLI, the CPUE of age- 0 bream differed between catch sites and times of day. BIRNAU was the site with significantly higher abundances of bream and bream were more frequently caught at day. The reasons for this site- and time-dependent heterogeneity in bream catches may reflect differences in habitat features such as bottom substrate size and diel activity cycles. Bream seemed to be generally more abundant at the site BIRNAU, where they may find rocky bottom substrate providing shelter from predation or better foraging opportunities (Fischer \& Eckmann, 1997; Stoll, et al., 2008). The reduced catches of bream at night may result from a habitat shift towards deeper littoral areas after sunset, which were not accessible to the beach seine. The habitat shift towards deeper areas of the littoral zone may help bream to avoid the negative effects of surface waves on their growth during night, which they face in the most shallow area of the littoral zone (Stoll et al., 2008).

The mechanism, by which lake water level fluctuations can affect the breeding success of shore spawning fish has been demonstrated for eggs of lake sardine Acanthobrama terraesanctae in Lake Kinneret, Israel (Gafny et al., 1992). Clean substrates promoted egg attachment and enhanced their subsequent survival. Gafny et al. (1992) concluded, that lake sardine actively seek shallow habitats at time of lake water level increase to spawn their eggs under conditions that allow optimum egg attachment. Accordingly, the bream eggs in our experiment attached better to and had a four-times higher survival rate on the clean than on the epiphyton-covered tile surfaces. Bream eggs were also most abundant at the shallowest depth with low epilithon cover in the natural spawning habitat. Though within the present study bream egg abundance was measured only during one season, similar distribution patterns have been observed in previous years (Wittkugel, 2002). The preference of epiphyton-free substrates by shore-spawning fish has also been documented for yellow perch 
(Perca flavescens) selecting submerged wood (Fisher et al., 1996) as well as for American smelt Osmerus mordax (Rupp, 1965).

In Lake Constance the abundance of epilithon is related to the period of inundation Peters, et al., 2007. At the time of the survey on egg abundance at the 18.05.2005 the four depth strata $(0-10,10-20,20-30,30-40 \mathrm{~cm}$ depth) have been inundated for approximately 13, 15, 24 and 38 days, respectively. The abundance of AFDM and IM in these depth strata corresponded well to the abundance of AFDM and IM observed by Peters et al. (2007) for the corresponding inundation periods. This fact further supports the prerequisite of our hypothesis that the period of inundation determines the amount of epilithon on the spawning substratum. The depth-gradient in epilithon cover observed in the spawning habitat in 2005 therefore reflects the duration of inundation and is consequently related to SpWLI. Unfortunately, the setup of the experiment failed to produce various degrees of epilithon cover and the epilithon density on the tiles was much lower than at the spawning site of bream. However, seven days of exposure sufficed to produce an epilithon cover on the tile surfaces adverse to egg attachment. Longer exposure periods can be expected to cause higher degrees of epilithon coverage (Peters et al., 2007) and should therefore have even more severe impacts on egg attachment.

Lake Constance is one of the few lakes of the alpine region of central Europe without a regulated outlet. Its water level follows a annual cycle typical for unregulated water bodies in temperate zones with a pronounced water level increases during spring, a stagnating or reducing water level during summer and decreasing water level in winter. However, bream can also be very abundant in water bodies with regulated water levels (e.g. low-land lakes and rivers) and the lack of SpWLI in these populations does not seem to affect their abundance. This may be due to the preference of spawning habitats with submerged macrophytes (Kafemann et al.,1998; Gerstmeier \& Romig, 2003), which grow during the spawning season of bream. In contrast to old shoots that have been colonized by periphyton, new shoots of 
macrophytes are periphyton-free and should allow good egg adhesion (Dziekonska, 1956). Further, the carrying capacity for bream should be generally higher in shallow eutrophic lakes than in oligotrophic prealpine lakes such as Lake Constance (Mehner et al., 2005).

In prealpine lakes with low abundance of macrophytes the strong seasonal lake water level increment before and during the spawning season appears to be crucial for the breeding success of bream. However, during the last century water levels have reduced in Lake Constance (Luft, 1993; Ostendorp et al., 2004) and future climate scenarios for South Germany predict a decrease in spring flood peaks (KLIWA, 2006; KLIWA, 2007). Reduced SpWLI should therefore affect many shallow water spawning fish, because the attachment and survival of their eggs may be reduced by epiphyton cover on spawning substrata and desiccation during egg incubation.

\section{Conclusions}

The results of the present study confirm the importance of lake water level increase prior to spawning for the breeding success of bream. Other hydrological and climate factors did not affect the abundance of 0 -age bream two months after hatch. In prealpine lakes with low densities of submersed vegetation bream therefore seem to rely on pristine spawning habitat, which will be only accessible in years with high spring water level increase. Climate change may reduce the amount of spring water level increase in lakes such as Lake Constance and may thus provide a threat to the successful breeding of bream.

\section{Acknowledgements}


We thank Alfred Sulger for the catch of parent bream, Bärbel Beese and Myriam Schmid for Chl $a$ determination, Martin Wolf for technical support, and Iris Töpfer and Diana Schleuter for assistance in the field. Data on water temperature in May were provided by the Institut für Seenforschung, Langenargen and the International Water Commission of Lake Constance (IGKB). This study was supported by the German Research Foundation (DFG) within the Collaborative Research Center 454 "Littoral Zone of Lake Constance" and a personal grant to Stefan Stoll by the German National Academic Foundation.

\section{References}

Aalto, S. K. \& G. E. Newsome, 1993. Winds and the demic structure of a population of yellow perch (Perca flavescens). Canadian Journal of Fisheries \& Aquatic Sciences 50: 496501.

Argillier, C., N. Poulet \& P. Irz, 2004. Effect of meteorological conditions and water level fluctuations on the year-class strength of pikeperch (Sander lucioperca L.) and perch (Perca fluviatilis L.) in a French reservoir. Ecohydrology \& Hydrobiology 4: 441-448.

Clark, M. E., K. A. Rose, J. A. Chandler, T. J. Richter, D. J. Orth \& W. Van Winkle, 1998. Simulating smallmouth bass reproductive success in reservoirs subject to water level fluctuations. Environmental Biology of Fishes 51: 161-174.

Clark, M. E., K. A. Rose, J. A. Chandler, T. J. Richter, D. J. Orth \& W. Van Winkle, 2008. Water-level fluctuation effects on Centrarchid reproductive success in reservoirs: A modelling analysis. North American Journal of Fisheries Management 28: 1138-1156. 
Dziekonska, J., 1956. Studies on embryonic development of fish. I. Observations on the spawning and the embryonic development of bream in the Vistula Lagoon. Polskie Archivum Hydrobiologii 3: 291-305.

Fischer, P. \& R. Eckmann, 1997. Spatial distribution of littoral fish species in a large European lake, Lake Constance, Germany. Archiv für Hydrobiologie 140: 91-116.

Fulford, R. S., J. A. Rice, T. J. Miller \& F. P. Binkowski, 2006a. Elucidating patterns of sizedependent predation on larval yellow perch (Perca flavescens) in Lake Michigan: an experimental and modelling approach. Canadian Journal of Fisheries \& Aquatic Sciences 63: $11-27$.

Fulford, R. S., J. A. Rice, T. J. Miller, F. P. Binkowski, J. M. Dettmers \& B. Belonger, 2006b. Foraging selectivity by larval yellow perch (Perca flavescens): Implications for understanding recruitment in small and large lakes. Canadian Journal of Fisheries \& Aquatic Sciences 63: $28-42$.

Gafny, S., A. Gasith \& M. Goren, 1992. Effect of water level fluctuation on shore spawning of Mirogrex terraesanctae (Steinitz), (Cyprinidae) in Lake Kineret, Israel. Journal of Fish Biology 41: 863-871.

Gerstmeier, R. \& T. Romig, 2003. Die Süßwasserfische Europas. Kosmos, Stuttgart. 
Herzig, A. \& H. Winkler, 1986. The influence of temperature on the embryonic development of three cyprinid fishes, Abramis brama, Chalcalburnus chalcoides mento and Vimba vimba. Journal of Fish Biology 28: 171-181.

Hladik, M. \& J. Kubecka, 2004. The effect of water level fluctuation on tributary spawning migration of reservoir fish. Ecohydrology \& Hydrobiology 4: 449-457.

Hurrell, J. W., Y. Kushnir, G. Ottersen \& M. Visbeck, 2003. An Overview of the North Atlantic Oscillation. In Hurrell, J. W., Kushnir, Y., Ottersen, G. \& M. Visbeck (eds), The North Atlantic Oscillation: Climatic Significance and Environmental Impact. American Geophysical Union, Washington DC: 1-30.

Jennings, S., M. J. Kaiser \& J. D. Reynolds, 2001. Marine fisheries ecology. Blackwell Science, Oxford.

Kafemann, R., R. Thiel, J. E. Finn \& R. Neukamm, 1998. The role of freshwater habitats for the reproduction of common bream Abramis brama (L.) in a brackish water system. Polskie Archivum Hydrobiologii 45: 225-244.

Kahl, U., S. Hülsmann, R. J. Radke \& J. Benndorf, 2008. The impact of water level fluctuations on the year class strength of roach: Implications for fish stock management. Limnologica 38: 258-268.

KLIWA, 2006. Regionale Klimaszenarien für Süddeutschland. KLIWA, Karlsruhe.

KLIWA, 2007. Zum Einfluss des Klimas auf den Bodensee. KLIWA, Karlsruhe. 
511 Kucharczyk, D., M. Luczynski, R. Kujawa \& P. Czerkies, 1997. Effect of temperature on

512 embryonic and larval development of bream (Abramis brama L.). Aquatic Sciences 59: 214513224.

Leggett, W. C. \& E. Deblois, 1994. Recruitment in marine fishes: Is it regulated by starvation 516 and predation in the egg and larval stages? Netherlands Journal of Sea Research 32: 119-134. Lorenzen, C. J., 1967. Determination of chlorophyll and phaeopigments: spectrometric equations. Limnology \& Oceanography 12: 343-346.

Lozan, J. L. \& H. Kausch, 1998. Angewandte Statistik für Naturwissenschaftler. Blackwell, 521 Berlin.

Luft, G., 1993. Langfristige Veränderungen der Bodensee-Wasserstände und mögliche Auswirkungen auf Erosion und Ufervegetation. In Ostendorp, W. \& P. Krumscheid-Plankert (eds), Seeuferzerstörung und Seeuferrenaturierung in Mitteleuropa. Schweitzerbart, Stuttgart: $1-75$.

Mehner, T., M. Diekmann, U. Braemick \& R. Lemcke, 2005. Composition of fish communities in German lakes as related to lake morphology, trophic state, shore structure and human-use intensity. Freshwater Biology 50: 70-85. 226. 
Mürle, U., J. Ortlepp \& P. Rey, 2004. Der Bodensee: Zustand-Fakten-Perspektiven.

Internationale Gewässerschutzkommission für den Bodensee (IGKB), Bregenz.

Nõges, P. \& A. Jarvet, 2005. Climate driven changes in the spawning of roach (Rutilus rutilus (L.)) and bream (Abramis brama (L.)) in the Estonian part of the Narva River basin. Boreal Environment Research 10: 45-55.

Nunn, A. D., I. G. Cowx, P. A. Frear \& J. P. Harvey, 2003. Is water temperature an adequate predictor of recruitment success in cyprinid fish populations in lowland rivers? Freshwater Biology 48: 579-588.

Ostendorp, W., K. Schmieder \& K. Jöhnk, 2004. Assessment of human pressures and their hydromorphological impacts in lakeshores in Europe. Ecohydrology \& Hydrobiology 4: 379395.

Ozen, O. \& R. L. Noble, 2002. Relationship between water level fluctuations and largemouth bass spawning in a Puerto Rico Reservoir. In Philipp, D. P. \& M. S. Ridgway (eds), Black bass: Ecology, conservation, and management. American Fisheries Society, Bethesda: 213220.

Paxton, C. G. M., I. J. Winfield, J. M. Fletcher, D. G. George \& D. P. Hewitt, 2004. Biotic and abiotic influences on the recruitment of male perch in Windermere, U.K. Journal of Fish Biology 65: 1622-1642.

Peters, L., N. Scheifhacken, M. Kahlert \& K.-O. Rothhaupt, 2005. An efficient in situ method for sampling periphyton in lakes and streams. Archiv für Hydrobiologie 163: 133-141. 
Peters, L., M. A. Wetzel, W. Traunspurger \& K.-O. Rothhaupt, 2007. Epilithic communities in a lake littoral zone: the role of water-column transport and habitat development for dispersal and colonization of meiofauna. Journal of the North American Benthological Society 26: 232-243.

Poncin, P., J. C. Philippart \& J. C. Ruwet, 1996. Territorial and non-territorial spawning behaviour in the bream. Journal of Fish Biology 49: 622-626.

Stoll, S., P. Fischer, P. Klahold, N. Scheifhacken, H. Hofmann \& K.-O. Rothhaupt, 2008. Effects of water depth and hydrodynamics on the growth and distribution of juvenile cyprinids in the littoral zone of a large pre-alpine lake. Journal of Fish Biology 72: 10011022.

Straile, D. \& N. C. Stenseth, 2007. The North Atlantic Oscillation and ecology: links between historical time-series, and lessons regarding future climate warning. Climate Research 34: 259-262.

Wilcox, D. A. \& J. E. Meeker, 1992. Implications for faunal habitat related to altered macrophyte structure in regulated lakes in northern Minnesota. Wetlands 12: 192-203.

Winfield, I. J., J. M. Fletcher \& J. B. James, 2004. Modelling the impacts of water level fluctuations on the population dynamics of whitefish (Coregonus lavaretus (L.)) in Haweswater, UK. Ecohydrology \& Hydrobiology 4: 409-416. 
Wittkugel, C., 2002. Entwicklung eines Laichhabitatsindexes für uferlaichende Fischarten im Bodensee. Dissertation, University Konstanz, Konstanz. 
Table 1: The response variable (bream CPUE) and factors (in italic) entered in the general liner regression model for the analysis of hydrological and climate influences on the abundance of YOY bream in Lake Constance.

\begin{tabular}{|c|c|c|c|}
\hline $\begin{array}{l}\text { Response variable/ } \\
\text { factor }\end{array}$ & Levels & Description & Abbreviation \\
\hline Catch per unit effort & Continuous & No. of bream caught per haul & CPUE \\
\hline Location & $\begin{array}{l}2 \text { (BIRNAU, }^{\text {BIRLS })^{\mathrm{a}}} \\
\text { FEL }^{2}\end{array}$ & Location of beach seine catch & Loc \\
\hline Time of catch & 2 (Day, Night) & Time of beach seine catch & Tim \\
\hline $\begin{array}{l}\text { Spring water level } \\
\text { increase }\end{array}$ & Continuous & $\begin{array}{c}\text { Difference between absolute } \\
\text { mean water levels in May and } \\
\text { April }\end{array}$ & SpWLI \\
\hline Water level in May & Continuous & $\begin{array}{c}\text { Absolute mean water level in } \\
\text { May }\end{array}$ & WL May \\
\hline Summer water level & Continuous & $\begin{array}{l}\text { Average of absolute mean } \\
\text { water levels in June and July }\end{array}$ & SuWL \\
\hline Cumulative degree days & Continuous & $\begin{array}{c}\text { The daily summation of } \\
\text { monthly mean air } \\
\text { temperatures from May, June, } \\
\text { July and August }\end{array}$ & DD \\
\hline Mean summer $N A O$ & Continuous & $\begin{array}{l}\text { The mean of monthly NAO } \\
\text { indices from May, June and } \\
\text { July }\end{array}$ & SNAO \\
\hline Mean winter $N A O$ & Continuous & $\begin{array}{l}\text { The mean of monthly NAO } \\
\text { indices from January, } \\
\text { February, March and April }\end{array}$ & WNAO \\
\hline
\end{tabular}

${ }^{\mathrm{a}}$ BIRNAU and FELS are the names of the two sampling sites, details see text and Fig.1. 
Table 2: Results of the general linear model (GLM) iteration for minimization of the Akaike Information Criterion (AIC). The initial GLM model was CPUE $\sim$ Loc $*$ Tim + SpWLI + WL $\mathrm{May}+\mathrm{SuWL}+\mathrm{DD}+\mathrm{SNAO}+\mathrm{WNAO}$, where $*$ indicates a full factorial and + a main effect analysis between the corresponding factors. stands for the influence of the environmental factors on the right hand side of the formula on the bream CPUE (response variable). From the initial model a stepwise reduction of non-influential factors on CPUE occurred, until a maximal AIC was achieved after five iterations.

\begin{tabular}{|c|c|c|c|c|c|c|c|}
\hline Model at... & AIC & Model R ${ }^{2}$ & Model P & Factors & Df & $\mathbf{F}$ & $\mathbf{P}$ \\
\hline \multirow[t]{9}{*}{...start } & 712.39 & 0.29 & $<0.001$ & Loc & 1 & 4.076 & 0.045 \\
\hline & & & & Tim & 1 & 8.866 & 0.003 \\
\hline & & & & Loc * Tim & 1 & 400.000 & 0.083 \\
\hline & & & & SpWLI & 1 & 4741.90 & $<0.001$ \\
\hline & & & & WL May & 1 & 19.8 & 0.699 \\
\hline & & & & SuWL & 1 & 74.0 & 0.455 \\
\hline & & & & DD & 1 & 14.1 & 0.744 \\
\hline & & & & SNAO & 1 & 111.4 & 0.359 \\
\hline & & & & WNAO & 1 & 195.5 & 0.225 \\
\hline \multirow{4}{*}{$\begin{array}{c}\text {..end } \\
\text { (5 Iterations) }\end{array}$} & 705.74 & 0.27 & $<0.001$ & Loc & 1 & 4.131 & 0.044 \\
\hline & & & & Tim & 1 & 8.986 & 0.003 \\
\hline & & & & Loc*Tim & 1 & 400.000 & 0.082 \\
\hline & & & & SpWLI & 1 & 36.501 & $<0.001$ \\
\hline
\end{tabular}


Table 3: Results of Wilcoxon-tests for matched pairs comparing relative survival rates of viable eggs on bare control and epilithon covered tile surfaces from day 1 to day 8 post fertilisation (Dpf). Mean percentage survival rates $( \pm$ S.E.) are shown.

\begin{tabular}{|c|c|c|c|c|c|c|}
\hline \multirow[t]{2}{*}{ Dpf } & \multicolumn{2}{|c|}{ Mean survival (\%) } & \multirow[t]{2}{*}{$\mathbf{N}$} & \multirow[t]{2}{*}{$T^{a}$} & \multirow[t]{2}{*}{$\mathbf{Z}^{\mathbf{b}}$} & \multirow[t]{2}{*}{$\mathbf{P}^{\mathbf{c}}$} \\
\hline & Clean & Epilithon & & & & \\
\hline 1 & $14.46( \pm 0.90)$ & $6.34( \pm 0.62)$ & 94 & 501 & 6.45 & $<0.001$ \\
\hline 4 & $12.82( \pm 0.87)$ & $5.15( \pm 0.80)$ & 94 & 418 & 6.70 & $<0.001$ \\
\hline 6 & $2.44( \pm 0.03)$ & $1.06( \pm 0.44)$ & 94 & 323 & 5.19 & $<0.001$ \\
\hline 8 & $0.86( \pm 0.20)$ & $0.19( \pm 0.09)$ & 94 & 92.5 & 4.03 & $<0.001$ \\
\hline & \multicolumn{6}{|c|}{$\mathrm{T}$ is the rank sum of matched pairs differences R (Lozan \& Kausch, 1998) } \\
\hline $\mathrm{b}$ & \multicolumn{6}{|c|}{$\mathrm{Z}$ refers to $\mathrm{z}$-transformation of R-value } \\
\hline & \multicolumn{6}{|c|}{$\mathrm{P}$ indicates significance threshold derived from Z-standardized normal } \\
\hline
\end{tabular}




\section{Figure captions}

Fig.1: Map of Lake Constance and locations of beach seining (grey stars), the substratum experiment (white star) and the natural bream spawning habitat (black area).

Fig.2: Hydrological (white) and climate factors (black) analysed by a general linear model to assess the importance of the catch per unit effort (CPUE, grey, \pm S.E.) of juvenile bream. A) Spring water level increase form April to May, B) Absolute mean water level in May, C) mean water level in June and July, D) cumulative numbers of degree days from May, June, July and August, E) the mean summer NAO indices, F) mean winter NAO index and G) mean bream CPUE from 1997 to 2008. For a detailed description of factors and the response variable please refer to Table 1.

Fig.3: The relationship between spring water level increase (SpWLI) and catch per unit effort (CPUE). A) SpWLI and CPUE between 1997 and 2008. B) Linear correlation between SpWLI and CPUE: CPUE $=0.188 * \operatorname{SpWLI}(\mathrm{cm})-4.236, \mathrm{~N}=12, \mathrm{p}<0.001$.

Fig. 4: The influence of epilithon on egg attachment and survival. A) Absolute number of viable eggs (mean \pm S.E.) attached to clean controls (black, $n=94$ ) and epilithon covered tiles (grey, $n=94)$. B) Percentage egg survival (mean \pm S.E.) from day 1 until day 8 post fertilisation (dpf). Asterisks indicate significant differences between samples from the same sampling day.

Fig. 5: Depth distribution of A) ash-free dry mass (AFDM), B) inorganic matter (IM), C) algae biomass (Chl $a$ ) and D) bream eggs (all mean \pm S.E.) in a natural bream spawning habitat of Lake Constance. Letters indicate homogenous groups of means determined by 
Tukey HSD-test. The dashed lines represent the mean abundance of AFDM, IM and Chl $a$ on the exposed tiles for comparison. 
Figure 1
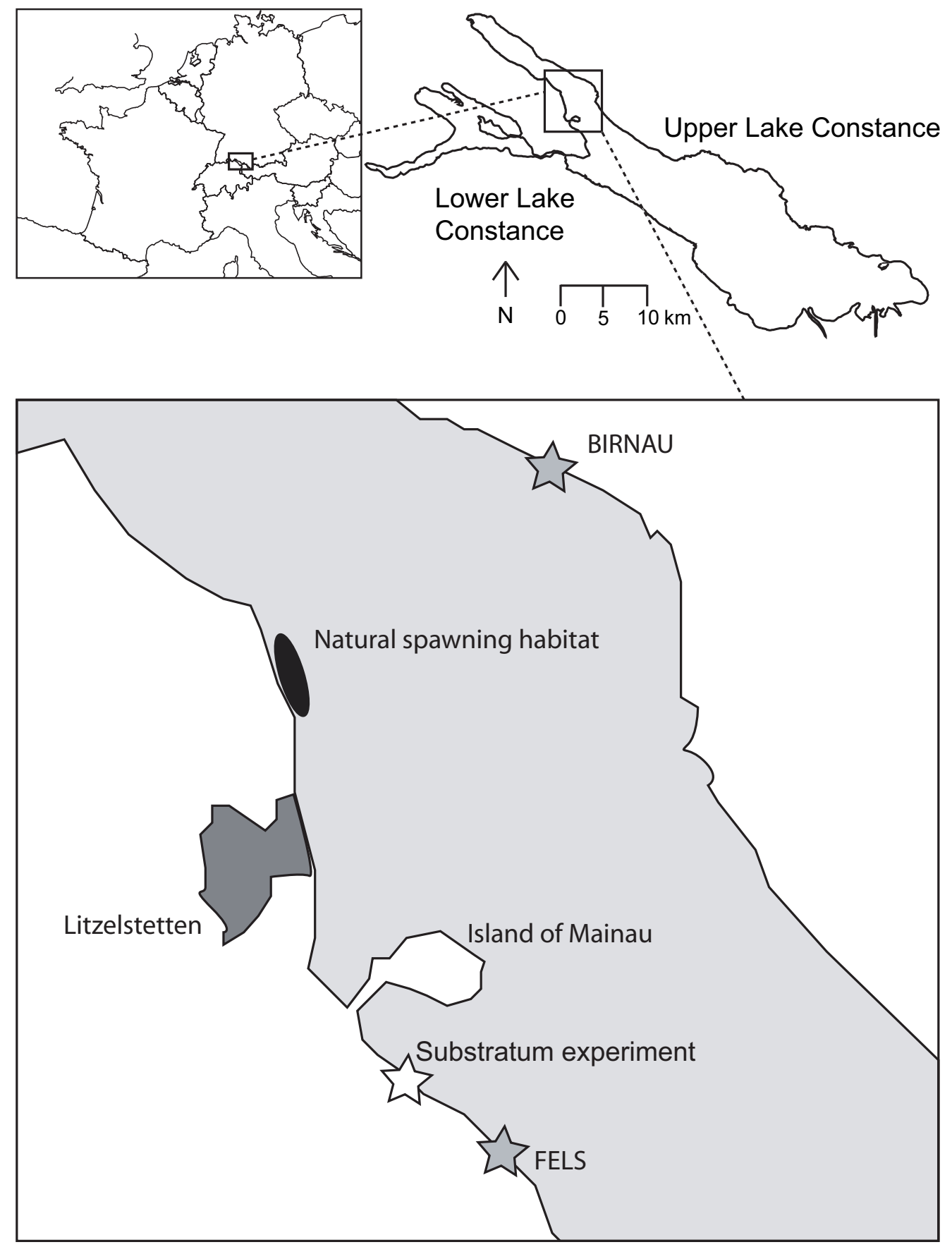
Figure 2
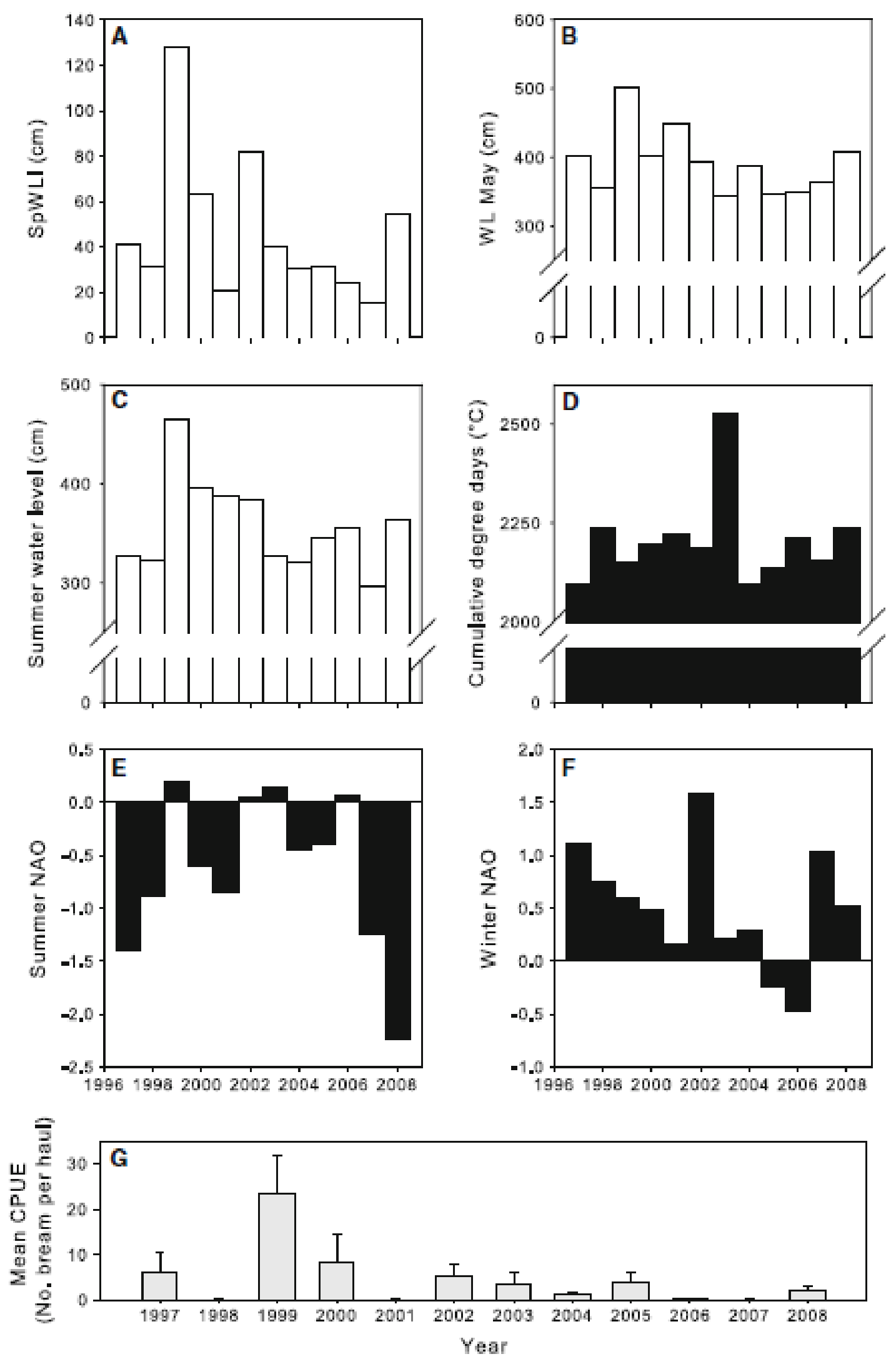
Figure 3
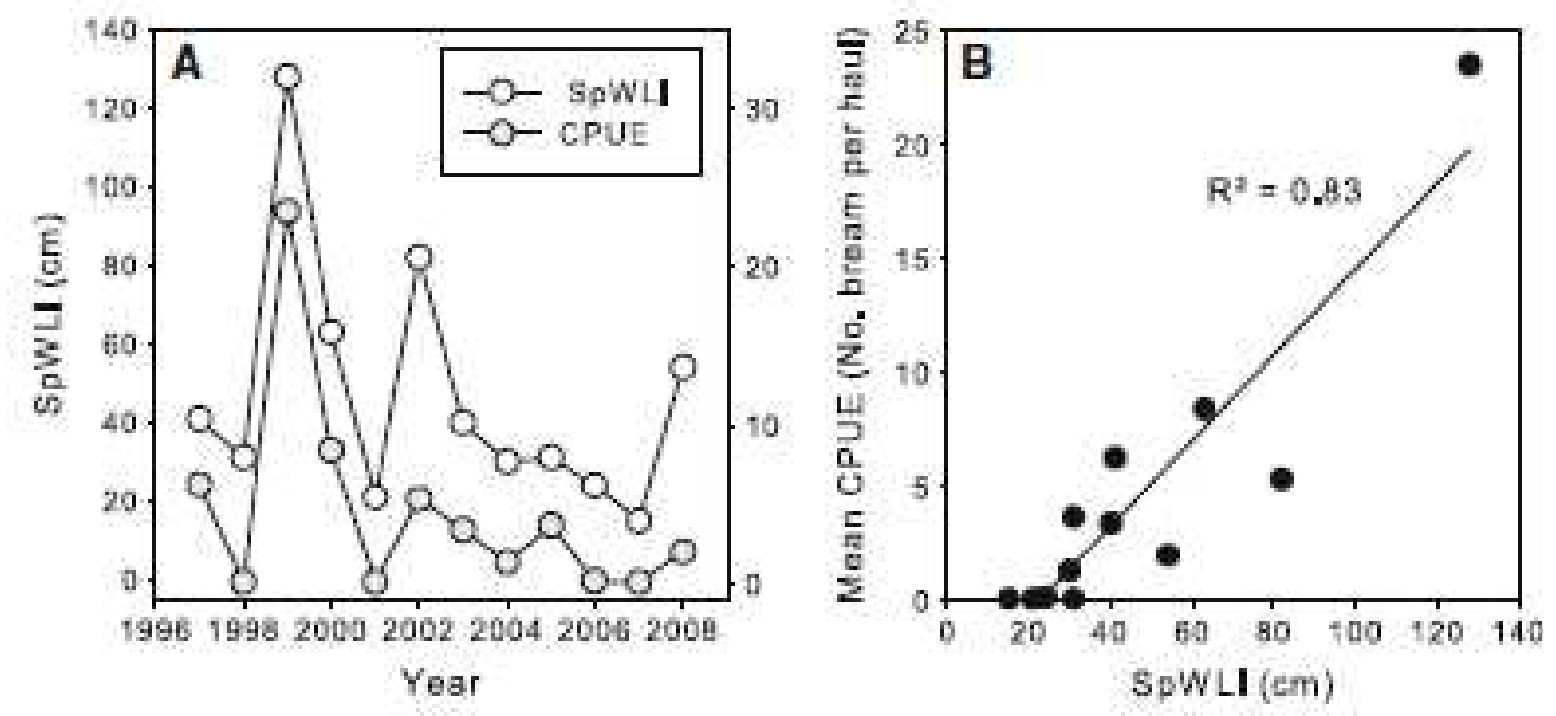
Figure 4

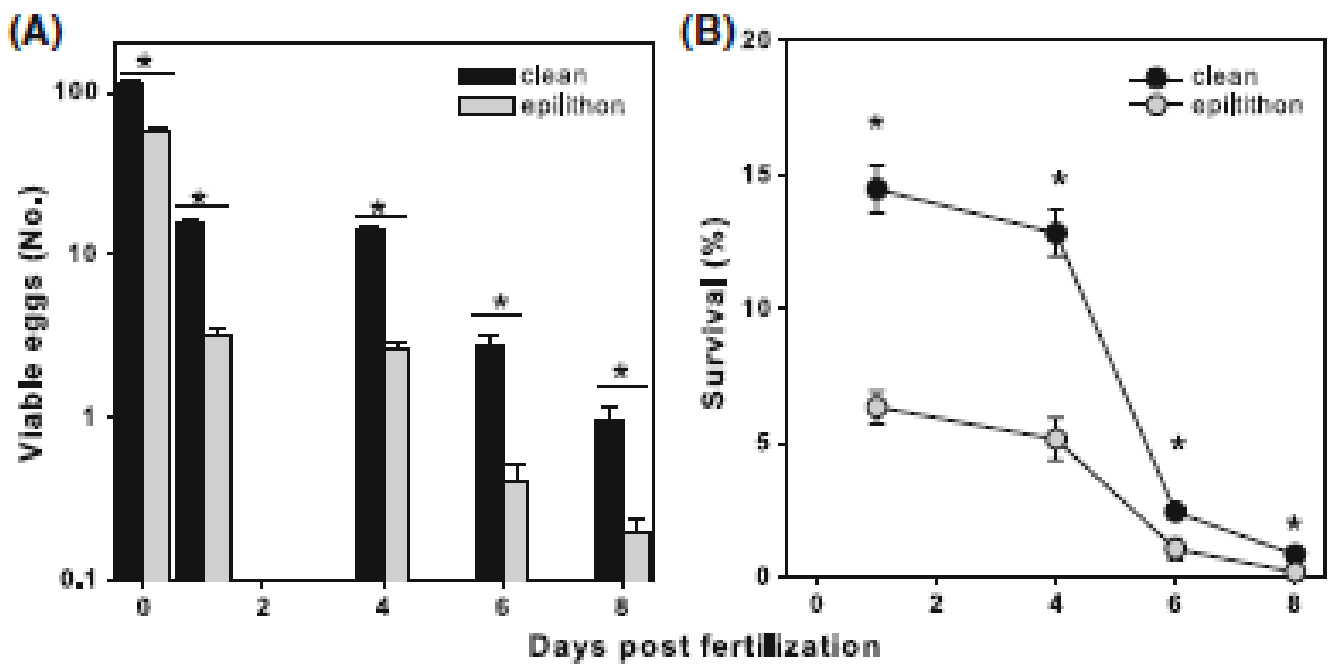


Figure 5
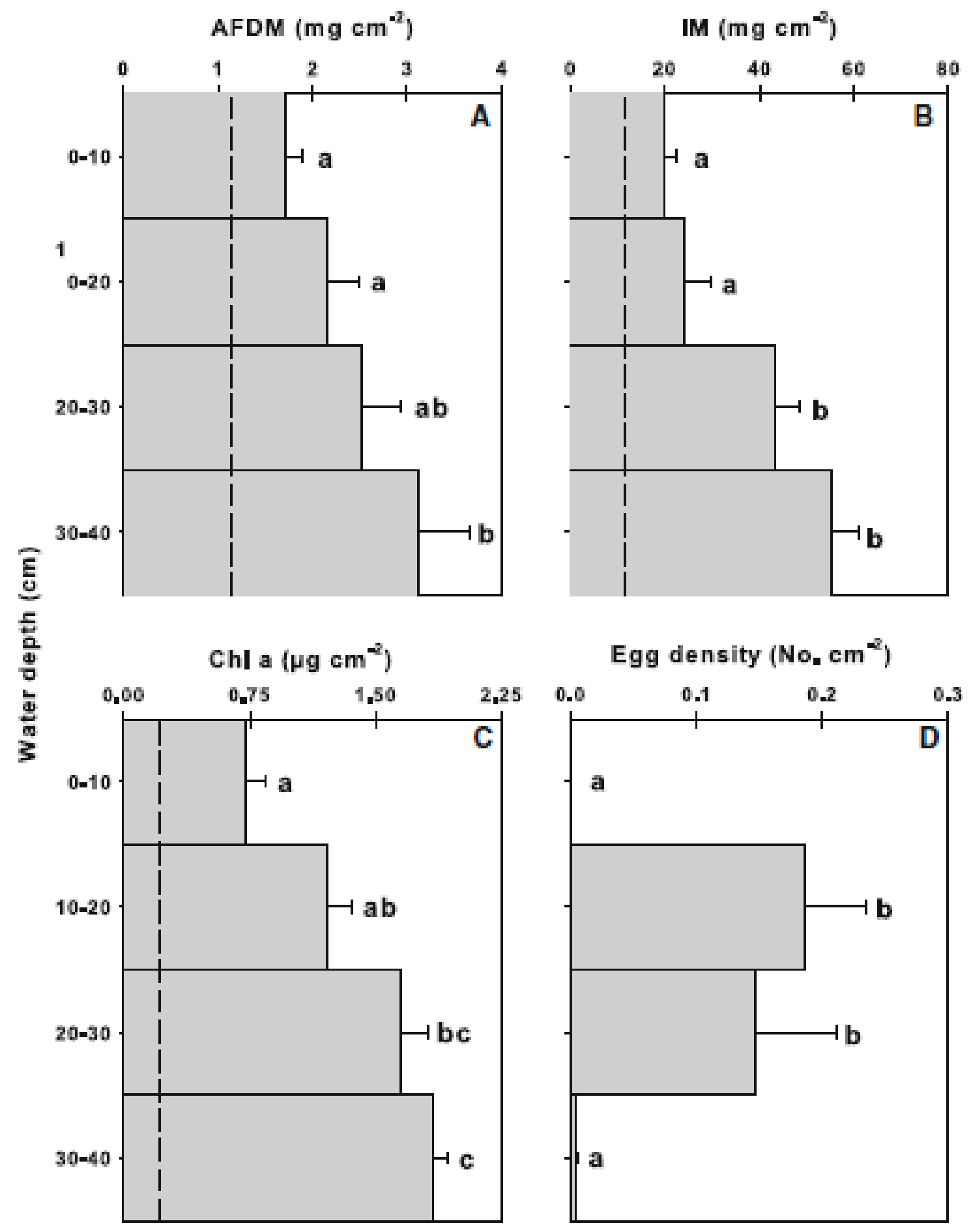